\title{
SPECIAL LOTTERY DRAWINGS - ANALYSIS OF AN UNCONVENTIONAL INVESTMENT OPPORTUNITY
}

\author{
Jaques Deivinson da Silva Castello ${ }^{1}$ and Armando Zeferino Milioni2* ${ }^{*}$
}

Received August 31, 2013 / Accepted June 14, 2014

\begin{abstract}
Quina Loto is one of the most popular lottery games in Brazil. Prizes are paid as a percentage of each drawing's revenues. After deductions and taxes, $34 \%$ of the revenues are destined for the payments of prizes on each drawing, $29 \%$ divided among winners and $5 \%$ saved in order to contribute for the major prize of the special drawing held annually, in June $24^{\text {th }}$. Due to the low expected return on investment, lotteries are widely regarded as a bad investment decision. Experience, however, shows that the special drawing might be an exception. In this paper we provide a thorough analysis of a theoretical investment in the special drawing of 2013, considering players' behavior, lesser prizes earnings, effects of the own investment in the jackpot, probabilities of sharing the prizes and outcomes covering methods. Finally, we compare our conclusions against the result of the lottery on June $24^{\text {th }}, 2013$.
\end{abstract}

Keywords: Lotto, Wallenius random variable, investment decision, applied probability, applied statistics.

\section{INTRODUCTION}

Loto III, widely known as Quina, was created in 1994 and today is the $3^{\text {rd }}$ most popular lottery game in Brazil, in terms of revenues. Drawings are held 6 times a week, from Monday to Saturday, and, in each of them, 5 numbers are randomly selected out of a pool of 80 numbers. Players, on the other hand, are allowed to select either 5,6 or 7 numbers, paying, respectively, $\mathrm{R} \$ 0.75$, $\mathrm{R} \$ 3.00$ or $\mathrm{R} \$ 7.50$ for each of these bets. Prizes are paid as a percentage of each drawing's revenues. After deductions and taxes, $34.1 \%$ of the revenues are destined for the payments of prizes on each drawing $-10.8 \%$ divided among players with 5 correct matches, $7.7 \%$ among those with 4 matches and $11.0 \%$ among those with 3 . The remaining $4.6 \%$, in turn, are saved in order to contribute for the major prize of the special drawing held annually, in June $24^{\text {th }}$, known as Quina de São João (see CEF, 2011 and 2012).

Due to the low expected return on investment, $29.5 \%$ for regular drawings as seen above, lotteries are widely regarded as a bad investment decision. Experience, however, shows that the

\footnotetext{
*Corresponding author.

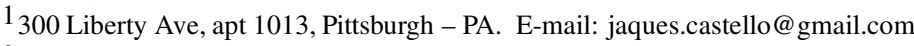

2 DCTA - ITA - IEMB, 12228-900 São José dos Campos, SP, Brazil. E-mail: milioni@ita.br
} 
special drawing might be an exception - first prize winners in 2012 drawing were awarded with $\mathrm{R} \$ 12.7$ million each while one could, theoretically, afford to play all the possible combinations for $\mathrm{R} \$ 8.6$ million.

The objective of this paper is to provide a thorough analysis of a theoretical investment in the special drawing of 2013, considering players' behavior, lesser prizes earnings, effects of the own investment in the jackpot, probabilities of sharing the prizes and outcomes covering methods.

\section{DEVELOPMENTS}

\subsection{Odds of winning}

Quina follows a fairly simple lottery model and players are considered winners when their bet contains 5,4 or 3 correct matches with the 5 numbers drawn in the raffle, hereby referred as $1^{\text {st }}, 2^{\text {nd }}$ and $3^{\text {rd }}$ prize tiers' winners, respectively. Odds of winning, for each of the prize tiers, follow a hypergeometric distribution which varies according to the amount of numbers selected, as illustrated in Table 1. It is important to notice that differently from other lottery games in Brazil, minor prizes winners receive a single prize even if they choose to play with multiple bets (6 or 7 numbers selected).

Table 1 - Odds of winning per prize tier.

\begin{tabular}{|c|c|c|c|}
\hline $\begin{array}{c}\text { Numbers } \\
\text { selected }\end{array}$ & $\begin{array}{c}1^{\text {st }} \text { tier } \\
(5 \text { matches })\end{array}$ & $\begin{array}{c}2^{\text {nd }} \text { tier } \\
(4 \text { matches })\end{array}$ & $\begin{array}{c}3^{\text {rd }} \text { tier } \\
(3 \text { matches })\end{array}$ \\
\hline 5 & $\frac{1}{24,040,016}$ & $\frac{1}{64,017}$ & $\frac{1}{866}$ \\
\hline 6 & $\frac{1}{4,006,669}$ & $\frac{1}{21,658}$ & $\frac{1}{445}$ \\
\hline 8 & $\frac{1}{1,144,763}$ & $\frac{1}{9,409}$ & $\frac{1}{261}$ \\
\hline
\end{tabular}

\subsection{Economical imbalance of bets}

One of the main contributing factors for the positive expected return on investment is the economical imbalance of bets. As mentioned before, players are allowed to select 5, 6 or 7 numbers on each bet, paying, respectively $\mathrm{R} \$ 0.75, \mathrm{R} \$ 3.00$ or $\mathrm{R} \$ 7.50$. Chances of winning however do not follow the same proportion. While those who choose to play with 5 numbers cover one single output for each bet, those who play 7 numbers cover a total of $\left(\begin{array}{l}7 \\ 5\end{array}\right)=21$ possible outputs, but paying only $10 \times$ the price for it, as illustrated in Table 2 . This turns outs to constitute a particular economical advantage in the special drawing of June 24 , in which the major prize largely outnumbers the minor prizes. 
Table 2 - Outputs vs. price comparison.

\begin{tabular}{|c|c|c|c|}
\hline $\begin{array}{c}\text { Numbers } \\
\text { selected }\end{array}$ & $\begin{array}{c}\text { Outputs } \\
\text { covered }\end{array}$ & Price & $\begin{array}{c}\text { Outputs/ } \\
\text { price ratio }\end{array}$ \\
\hline 5 & 1 & $\mathrm{R} \$ 0.75$ & 1.33 \\
\hline 6 & 6 & $\mathrm{R} \$ 3.00$ & 2.00 \\
\hline 7 & 21 & $\mathrm{R} \$ 7.50$ & 2.80 \\
\hline
\end{tabular}

\subsection{Number of players per kind of ticket}

Given that the payout for gamblers varies according to the amount of numbers selected, it is important to understand how many of them will choose to play 5, 6 or 7 numbers. This information, however, is not disclosed by CEF, the lottery manager, and estimation methods are necessary to derive an answer.

For the period analyzed, information is available for the number of winners in each of the prize tiers and for the total revenues with bets. Let $N_{5}, N_{6}$ and $N_{7}$ represent the number of bets containing 5, 6 or 7 numbers, the number of winners in the analyzed period for each of the tiers can be estimated, with error $\varepsilon$, as:

$$
\left[\begin{array}{ccc}
\frac{1}{24,040,016} & \frac{1}{4,006,669} & \frac{1}{1,144,763} \\
\frac{1}{64,017} & \frac{1}{21,658} & \frac{1}{9,409} \\
\frac{1}{866} & \frac{1}{445} & \frac{1}{261}
\end{array}\right]\left[\begin{array}{c}
N_{5} \\
N_{6} \\
N_{7}
\end{array}\right]=\left[\begin{array}{c}
200 \\
45,461 \\
2,986,809
\end{array}\right]+\varepsilon
$$

To offset the difference in the magnitude between tiers, this equation can be rewritten as:

$$
\left[\begin{array}{ccc}
\frac{1}{200 \times 24,040,016} & \frac{1}{200 \times 4,006,669} & \frac{1}{200 \times 1,144,763} \\
\frac{1}{45,461 \times 64,017} & \frac{1}{45,461 \times 21,658} & \frac{1}{45,461 \times 9,409} \\
\frac{1}{2,986,809 \times 866} & \frac{1}{2,986,809 \times 445} & \frac{1}{2,986,809 \times 261}
\end{array}\right]\left[\begin{array}{l}
N_{5} \\
N_{6} \\
N_{7}
\end{array}\right]=\left[\begin{array}{l}
1 \\
1 \\
1
\end{array}\right]+\varepsilon^{\prime}
$$

Observing that the total revenues should add up to a total of $0.75 N_{5}+3.00 N_{6}+7.50 N_{7}=$ $2,605,662,369.00$, above equation can be solved by using the ordinary least squares method to minimize $\varepsilon^{\prime} \varepsilon^{\prime}$. Results suggest that $88.55 \%$ of bets contain 5 numbers, while $7.26 \%$ contain 6 and $4.17 \%$ contain 7 numbers.

These results also allow us to derive an average price for the ticket, $\bar{c}$, which is further used for calculating the number of tickets sold based on the sales in reais, so that:

$$
\bar{c}=88.55 \% \cdot 0.75+7.26 \% \cdot 3.00+4.19 \% \cdot 7.50=\mathrm{R} \$ 1.196
$$




\subsection{Evidence of players' bias}

While one could assume players select numbers randomly among those available in the pool, studies suggest that 'birthday numbers' ( 1 to 31 , referring to the day of the month) tend to be more popular than other numbers (Thaler \& Ziemba, 1988). This trend becomes evident when the percentage of winning tickets is plotted against the count of birthday numbers drawn among the winning numbers, as shown in Figure 1.

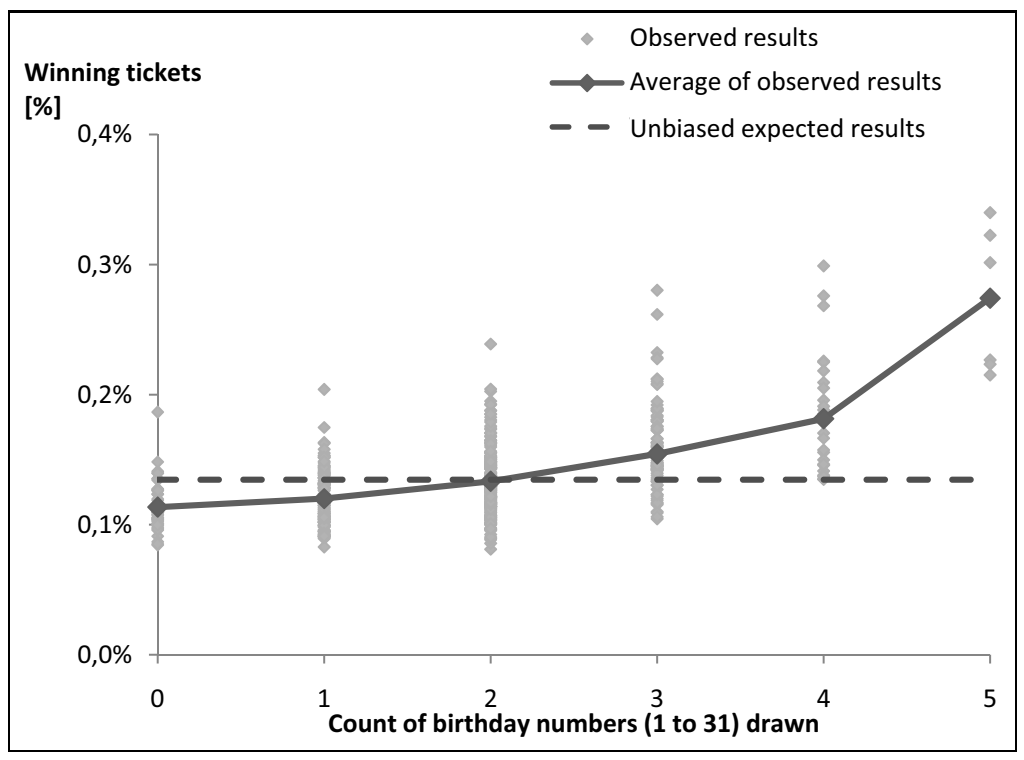

Figure $1-\%$ of winning tickets in $3^{\text {rd }}$ prize tier vs. count of 'birthday numbers'.

The same trend can be observed on Table 3, where the numbers are ordered according to the frequency that players pick them (CEF, 2012).

Table 3 - Numbers ordered according to the frequency that they are chosen.

\begin{tabular}{|c|c|c|c|c|c|c|c|c|c|}
\hline 70 & 61 & 50 & 66 & 60 & 76 & 38 & 71 & 31 & 58 \\
\hline 40 & 51 & 68 & 69 & 30 & 46 & 57 & 52 & 41 & 63 \\
\hline 73 & 80 & 39 & 59 & 64 & 36 & 74 & 77 & 67 & 65 \\
\hline 75 & 20 & 42 & 78 & 72 & 22 & 49 & 62 & 32 & 79 \\
\hline 29 & 47 & 28 & 45 & 44 & 56 & 21 & 23 & 54 & 53 \\
\hline 43 & 48 & 2 & 1 & 16 & 34 & 15 & 37 & 33 & 19 \\
\hline 55 & 8 & 35 & 27 & 26 & 24 & 18 & 12 & 17 & 11 \\
\hline 25 & 6 & 14 & 3 & 10 & 4 & 9 & 7 & 5 & 13 \\
\hline
\end{tabular}

As it can be seen, all 17 numbers most often picked are $=31$, and only 4 numbers $=31$ appear in the lower half of the Table. 


\subsection{Probability under bias conditions}

In order to understand how players' bias affects the distribution of the number of winners it is first necessary to calculate the odds of winning for a biased ticket, given a certain amount of birthday numbers are drawn among the winning ones. Supposing a player selects $n_{b}$ birthday numbers among $n$ numbers played, the probability that he or she gets $k$ correct matches given $t_{b}$ out of the 5 numbers drawn are also birthday numbers is given by:

$$
p(k)=\sum_{r=0}^{k} \operatorname{hypg}\left(r ; t_{b}, n_{b}, 31\right) \cdot \operatorname{hypg}\left(k-r ; 5-t_{b}, n-n_{b}, 49\right)
$$

where:

$$
\operatorname{hypg}(k ; t, n, m)=\frac{\left(\begin{array}{c}
n \\
k
\end{array}\right)\left(\begin{array}{c}
m-n \\
t-k
\end{array}\right)}{\left(\begin{array}{c}
m \\
t
\end{array}\right)}
$$

\subsection{Mathematical modeling of players behavior}

To model the population of players mathematically, two distinct categories were considered. Namely:

- Category A: fraction $\alpha$ of players who select numbers randomly. The probability $\varphi_{A}$ that $n_{b}$ birthday numbers are picked among the $n$ numbers played is given by a straightforward hypergeometric distribution.

$$
\varphi_{A}\left(n_{b} ; ; n\right)=\operatorname{hypg}\left(n_{b} ; n, 31,80\right)
$$

- Category B: fraction $\beta=(1-\alpha)$ of players who have a bias towards birthday numbers. For these players, birthday numbers were considered to be $\omega$ times more likely to be picked over non-birthday numbers, which leads to a Wallenius' non-central hypergeometric distribution (in the context of this paper, Wallenius' distribution was preferred over Fisher's to reflect the sequential, competitive, process when of the choice of numbers) for the number of birthday numbers picked, which means that the probability $\varphi_{B}$ that $n_{b}$ birthday numbers are picked among $n$ numbers played is given by:

$$
\varphi_{B}\left(n_{b} ; n\right)=\operatorname{wnchypg}\left(n_{b} ; n, 31,80, \omega\right)
$$

which is calculated recursively (Fog, 2008) by using the fact that:

$$
\begin{aligned}
\operatorname{wnchypg}(k ; t, n, m, \omega)= & \operatorname{wnchypg}(k-1 ; t-1, n, m, \omega) \\
& \times \frac{(n-k+1) \omega}{(n-k+1) \omega+m-t-n+k} \\
& +\operatorname{wnchypg}(k ; t-1, n, m, \omega) \\
& \times \frac{m-t-n+k+1}{(n-k) \omega+m-t+k+1}
\end{aligned}
$$


restricted to: wnchypg $(0 ; 0, n, m, \omega)=1$

$$
\begin{array}{ll}
\text { wnchypg }(k ; t, n, m, \omega)=0 ; & \forall k<0 \\
\text { wnchypg }(k ; t, n, m, \omega)=0 ; & \forall k>t
\end{array}
$$

Considering the $3^{\text {rd }}$ prize tier to minimize random variation, the expected number of winning bets considering $t_{b}$ birthday numbers are drawn in the raffle, $E\left(W_{3}\right)$, can be calculated as the sum of the expected number of winning bets for each of the categories of players and for each kind of bet within these categories. More specifically, considering the entire data set, the total number of winners when $t_{b}$ birthday numbers were drawn, given that the ticket sales added up to $R\left(t_{b}\right)$ can be estimated as:

\begin{tabular}{|c|c|c|}
\hline $\begin{array}{c}\text { Fraction of tickets } \\
\text { containing } \\
n \text { numbers }\end{array}$ & $\begin{array}{l}\text { Fraction of tickets } \\
\text { containing } n_{b} \\
\text { birthday numbers }\end{array}$ & $\begin{array}{l}\text { Individual probability of } \\
\text { winning a } 3^{\text {rd }} \text { tier prize } \\
\text { under bias conditions }\end{array}$ \\
\hline
\end{tabular}

$$
\begin{aligned}
E\left(W_{3}\right)=\frac{A}{\bar{c}} \times\{ & 88.55 \% \cdot \sum_{n_{b}=0}^{5}\left\{\left[\alpha \varphi_{A}\left(n_{b} ; 5\right)+\beta \varphi_{B}\left(n_{b} ; 5\right)\right]\right. \\
& \left.\times \sum_{k=0}^{3} \operatorname{hypg}\left(k ; t_{b}, n_{b}, 31\right) \cdot \operatorname{hypg}\left(3-k ; 5-t_{b}, 5-n_{b}, 49\right)\right\} \\
& +7.26 \% \cdot \sum_{n_{b}=0}^{6}\left\{\left[\alpha \varphi_{A}\left(n_{b} ; 6\right)+\beta \varphi_{B}\left(n_{b} ; 6\right)\right]\right. \\
& \left.\times \sum_{k=0}^{3} h y p g\left(k ; t_{b}, n_{b}, 31\right) \cdot \operatorname{hypg}\left(3-k ; 5-t_{b}, 6-n_{b}, 49\right)\right\} \\
& +4.19 \% \cdot \sum_{n_{b}=0}^{7}\left\{\left[\alpha \varphi_{A}\left(n_{b} ; 7\right)+\beta \varphi_{B}\left(n_{b} ; 7\right)\right]\right. \\
& \left.\left.\times \sum_{k=0}^{3} h_{y p g}\left(k ; t_{b}, n_{b}, 31\right) \cdot h_{y p g}\left(3-k ; 5-t_{b}, 7-n_{b}, 49\right)\right\}\right\}
\end{aligned}
$$

Stressing this expression numerically by using Frontline Systems Solver ${ }^{\circledR}$ Add-In for Microsoft Excel ${ }^{\circledR}$, it is possible to determine $\alpha$ and $\omega$ so that the difference between the observed and theoretical results is minimal in a least-squared sense, which yields:

$$
\left\{\begin{array}{l}
\alpha=69.0 \% \\
\omega=2.000
\end{array}\right.
$$

Considering these new results, it is possible to reconstruct Figure 1 so as to reflect the biasadjusted model for players' behavior, as illustrated in Figure 2. 


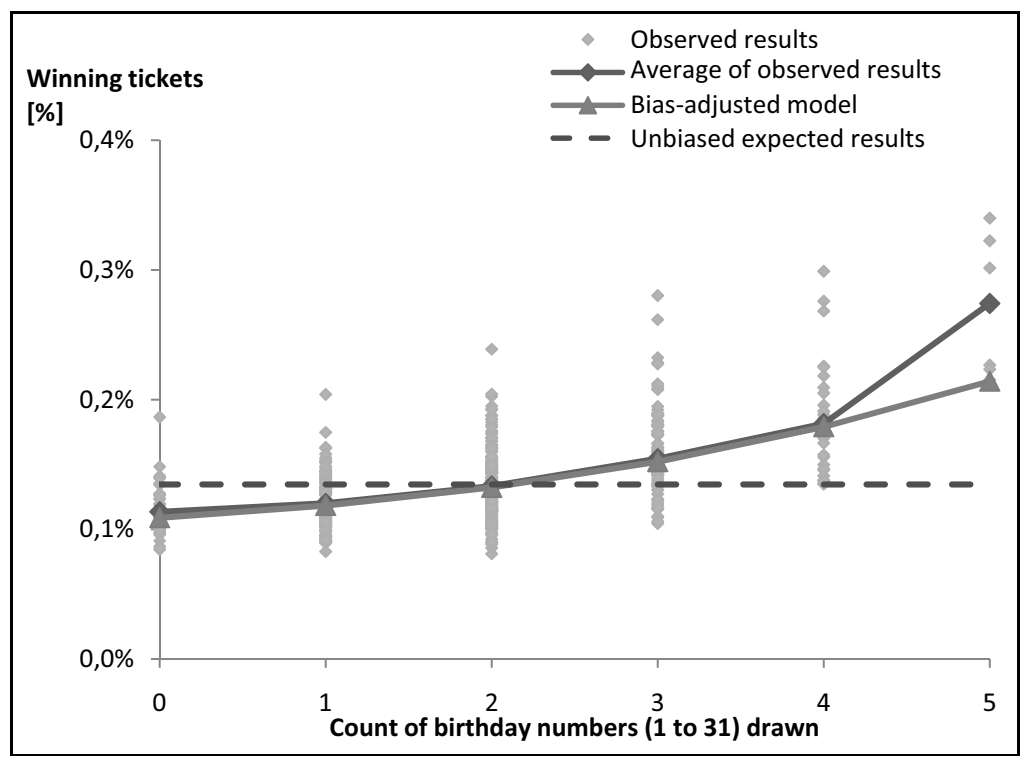

Figure 2 - Gordon et al., 1995 and Gründlich, 2004.

\subsection{The covering problem}

As previously shown, tickets with 6 and 7 numbers have an economical advantage over 5 numbers tickets, due to their higher output coverage for each real invested. However, while covering all of the $24,040,016$ possible 5-uple outcomes with tickets containing 5 numbers is a trivial problem, doing so with tickets containing 6 or more numbers is a combinatorial problem, known as 'the covering problem', which still has no closed solution (Burger et al., 2003a and 2003b). The problem is that, as the number of bets made rise, it becomes increasingly harder (and eventually impossible) to find a bet whose outputs do not overlap those of bets already made (see Gordon et al., 1995; Gründlich, 2004 and Du Plessis, 2010).

Hence, to determine a solution which approaches the optimal, a heuristic greedy algorithm was used. The algorithm starts by running through all the possible 7 number combinations and selecting those in which none of the 21 outputs covered overlap those of combinations already selected. Then, the no-overlap requirement is relaxed to allow 1 overlap among the 21 outputs covered and the procedure runs through all the possible 7 number combinations once more. Eventually, when the procedure would allow 7 overlaps per bet, it turns out that 6 number tickets with no output overlap become more advantageous for covering purposes and the algorithm then runs through all the 6 number combinations in a similar fashion.

The logic continues until all possible 5 number outputs are covered, always selecting the bet size and overlap requirements that yield the best coverage per real invested ratio. The results obtained are summarized in Table 4. 
Table 4 - Covering algorithm output.

\begin{tabular}{|c|c|c|c|c|c|}
\hline \multirow{2}{*}{$\begin{array}{l}\text { Ticket } \\
\text { type }\end{array}$} & \multirow{2}{*}{$\begin{array}{c}\text { Number of } \\
\text { tickets }\end{array}$} & \multirow{2}{*}{ Total cost } & \multirow{2}{*}{$\begin{array}{l}\text { Outputs } \\
\text { covered }\end{array}$} & \multicolumn{2}{|c|}{ Multiple coverage (variation) } \\
\hline & & & & $2 \times$ & $3 \times$ or above \\
\hline 7 & $1,113,809$ & $\mathrm{R} \$ 8,353,567.50$ & $20,282,735$ & $2,602,488$ & 244,371 \\
\hline 6 & 407,798 & $\mathrm{R} \$ \quad 1,223,394.00$ & $1,890,917$ & 406,092 & 71,626 \\
\hline 5 & $1,866,364$ & $\mathrm{R} \$ 1,399,773.00$ & $1,866,364$ & 0 & 0 \\
\hline Total & $3,387,971$ & $\mathrm{R} \$ 10,976,734.50$ & $24,040,016$ & $3,008,580$ & 315,997 \\
\hline
\end{tabular}

Results show that, while one could assume all of the possible outcomes could be covered with $1,144,763 \times \mathrm{R} \$ 7.50=\mathrm{R} \$ 8,585,722.50$, a $28 \%$ higher investment is, in fact, required to do so. On the other hand, several of the outputs are covered twice or more, which yields a $12.5 \%(1.3 \%)$ chance of having two (three) winning tickets in the $1^{\text {st }}$ prize tier.

\subsection{Expected jackpot - fixed part}

The jackpot for the special drawing of June 24 can be divided in two parts, a fixed part, which doesn't depend on the number of players, and a variable part, which grows proportionally to the drawing's revenues. The fixed part is composed by the fraction saved on the preceding regular drawings over a 1-year period, $A_{S}$, and by an eventual $1^{\text {st }}$ tier prize rolled over from the previous drawing, in case it had no winners, $A_{R}$.

To estimate the prize resulting from the fraction saved in regular drawings, the special drawing of 2012 was used as a proxy. For the 63 first regular drawings which contributed for the special drawing of 2012, the revenues added up to a total of $\mathrm{R} \$ 307,686,432.75$ and the amount saved in all the preceding regular drawings totaled $\mathrm{R} \$ 73,426,979.04$. The revenues of the first 63 regular drawings contributing for the special drawing of 2013, on the other hand, added up to a total of $\mathrm{R} \$ 325,800,059.25$ so it is expected that the amount saved for this drawing totals:

$$
A_{S}=\frac{325,800,059.25}{307,686,432.75} \times \mathrm{R} \$ 73,426,979.04=\mathrm{R} \$ 77,749,655.41
$$

An eventual rolled over prize from the previous drawing may also add up to this total. For the data analyzed the rolled over prize averages:

$$
A_{R}=\mathrm{R} \$ 985,456.76
$$

\subsection{Expected revenue}

As only 2 special drawings were held as of 2012, there's restricted data available to statistically estimate the revenue of 2013's drawing. Due to this limitation a hypothesis driven approach was used to derive an answer. As Figure 3 evidences, drawings' revenues are correlated to the estimated $1^{\text {st }}$ tier prize released by CEF prior to the drawing's realization $\left(R^{2}=0.88\right)$, with a linear coefficient of 0.892 . 
Assuming this same coefficient holds true for special drawings, one may infer the revenue for a drawing $R_{i}$ based on the previous drawing revenue $R_{i-1}$ and on the $1^{\text {st }}$ tier prize released by CEF for each of them, $J_{i}$ and $J_{i-1}$ :

$$
R_{i}-R_{i-1}=0.892 \times\left(J_{i}-J_{i-1}\right)
$$

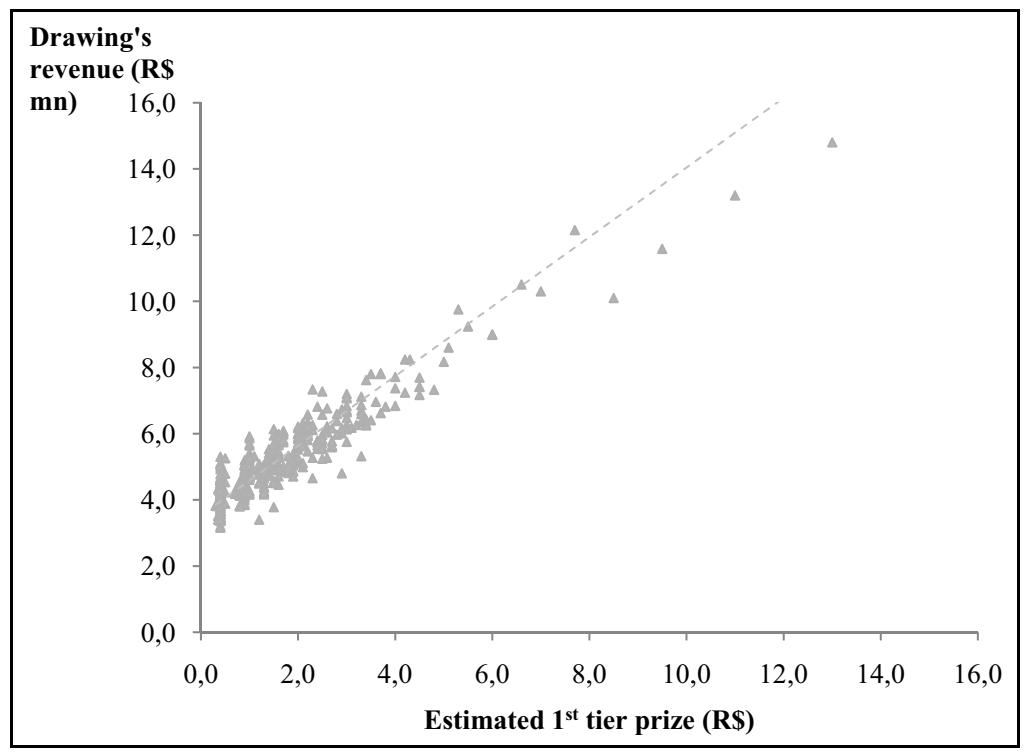

Figure 3 - Revenues vs. announced $1^{\text {st }}$ tier prize for regular drawings.

Assuming that CEF's estimates for the $1^{\text {st }}$ tier prize is equal to the actual prize and knowing that $15.41 \%$ of the revenues are reverted to the prize, this equation can be rewritten as:

$$
\begin{aligned}
R_{i}-R_{i-1} & =0.892 \times\left(\left(A_{R}+A_{S}+15.41 \% \times R_{i}\right)-J_{i-1}\right) \\
R_{i} & =\frac{0.892 \times\left(A_{R}+A_{S}-J_{i-1}\right)+R_{i-1}}{1-0.892 \times 15.41 \%}
\end{aligned}
$$

Plugging in $A_{R}$ and $A_{S}$ calculated in the previous section and knowing that for the previous special drawing $J_{i-1}=\mathrm{R} \$ 88,000,000.00$ and $R_{i-1}=\mathrm{R} \$ 101,013,611.25$, the equation yields:

$$
R_{i}=\mathrm{R} \$ 107,523,938.41
$$

which suggests a total number of tickets sold $N_{T}=89,884,645, N_{5}=79,589,643$ of which containing 5 numbers, $N_{6}=6,529,069$ containing 6 numbers and $N_{7}=3,765,934$ containing 7 . When the own investment is included $R_{i}$ becomes:

$$
R_{i}^{\prime}=118,500,672.91
$$




\subsection{Jackpot breakdown}

Considering the fixed part of the jackpot and the revenue of drawing, it is possible to break the jackpot down between each of the prize tiers, according to the rules defined by CEF, as shown in Table 5.

Table 5 - Jackpot breakdown after income tax by prize tier.

\begin{tabular}{|c|c|c|}
\hline Field & Description & Value $(\mathrm{R} \$)$ \\
\hline 1 & Total jackpot $=(2)+(6)+(8)$ & $115,249,195.12$ \\
\hline 2 & $1^{\text {st }}$ tier -5 correct matches (quina) $=(3)+(4)+(5)$ & $96,992,153.65$ \\
\hline 3 & $50 \%$ of revenue share destined to prizes & $18,257,041.47$ \\
\hline 4 & Amount saved from regular drawings & $77,749,655.41$ \\
\hline 5 & Rolled-over prize from previous drawing & $985,456.76$ \\
\hline 6 & $2^{\text {nd }}$ tier -4 correct matches $($ quadra $)=(7)$ & $9,128,520.74$ \\
\hline 7 & $25 \%$ of revenue share destined to prizes & $9,128,520.74$ \\
\hline 8 & $3^{\text {rd }}$ tier -3 correct matches $($ terno $)=(9)$ & $9,128,520.74$ \\
\hline 9 & $25 \%$ of revenue share destined to prizes & $9,128,520.74$ \\
\hline
\end{tabular}

\subsection{Prize sharing}

One of the key factors to take into account when analyzing lottery investments is the likelihood to share prizes with other players. Given a certain number of other players $N$ also take part in the game with a probability $p$ of winning, the number of winners follows a binomial distribution in which $n$ is the number of trials and $p$ is the success probability for each trial.

When $N$ is large and $p$ small, as in our case, this distribution strongly converges to a Poisson distribution with parameter $\lambda=N p$ (Simons, 1971), which keeps the useful property that the addition of Poisson distributed variables is also a Poisson distributed variable.

Considering that players have a bias towards selecting birthday numbers the parameter $\lambda$ varies significantly with the amount of numbers from 1 to 31 drawn, $t_{b}$. For instance, considering the population of players who select a total of $n$ numbers per bet, the expected number of players with $k$ correct matches, $\lambda$, considering $t_{b}$ birthday numbers were drawn in the raffle is given by the sum of the parameters for the subgroups of this population which selected $n_{b}$ birthday numbers or:

$$
\begin{gathered}
\lambda\left(k, n ; t_{b}\right)=N_{n} \sum_{n_{b}=0}^{n}\left\{\left[\alpha \varphi_{A}\left(n_{b} ; n\right)+\beta \varphi_{B}\left(n_{b} ; n\right)\right]\right. \\
\left.\times \sum_{r=0}^{k} \operatorname{hypg}\left(r ; t_{b}, n_{b}, 31\right) \operatorname{hypg}\left(k-r ; 5-t_{b}, n-n_{b}, 49\right)\right\}
\end{gathered}
$$


Table 6 summarizes the values for $\lambda\left(k, n ; t_{b}\right)$. Hence, knowing that the probability that $t_{b}$ birthday numbers will be drawn in the raffle is calculated as hypg $\left(t_{b}, 5,31,80\right)$, and if $X_{k}$ is the random variable that describes the number of third party winners with $k$ correct matches, then:

$$
p\left(X_{k}=x\right)=\sum_{t_{b}=0}^{5}\left\{\operatorname{hypg}\left(t_{b}, 5,31,80\right) \sum_{n=5}^{7} \frac{\left(\lambda\left(k, n ; t_{b}\right)\right)^{x} e^{\lambda\left(k, n ; t_{b}\right)}}{x !}\right\}
$$

Table 6 - Expected number of winners per prize tier and bet type $-\lambda$.

\begin{tabular}{|c|c|c|c|c|c|c|c|c|}
\hline$k$-correct & \multirow{2}{*}{$\begin{array}{c}n \text {-bet } \\
\text { matches }\end{array}$} & $N_{n}$-number & \multicolumn{5}{|c|}{$t_{b}$ - 'birthday numbers' drawn (probability of occurrence) } \\
\cline { 4 - 9 } & type & of players & $0(8 \%)$ & $1(27 \%)$ & $2(36 \%)$ & $3(22 \%)$ & $4(6 \%)$ & $5(1 \%)$ \\
\hline \multirow{4}{*}{5} & 5 & $79,589,643$ & 2.5 & 2.7 & 3.1 & 3.9 & 5.6 & 9.0 \\
\cline { 2 - 9 } & 6 & $6,529,069$ & 1.2 & 1.3 & 1.5 & 1.9 & 2.7 & 4.4 \\
\cline { 2 - 9 } & 7 & $3,765,934$ & 2.5 & 2.7 & 3.1 & 3.9 & 5.5 & 8.8 \\
\cline { 2 - 9 } & Total & $89,884,645$ & 6.2 & 6.7 & 7.7 & 9.7 & 13.9 & 22.3 \\
\hline \multirow{4}{*}{4} & 5 & $79,589,643$ & 960 & 1,044 & 1,191 & 1,445 & 1,870 & 2,549 \\
\cline { 2 - 9 } & 6 & $6,529,069$ & 234 & 254 & 290 & 351 & 452 & 612 \\
\cline { 2 - 9 } & 7 & $3,765,934$ & 311 & 338 & 385 & 465 & 597 & 805 \\
\cline { 2 - 9 } & Total & $89,884,645$ & 1,504 & 1,635 & 1,866 & 2,261 & 2,918 & 3,966 \\
\hline \multirow{4}{*}{3} & 5 & $79,589,643$ & 74,298 & 80,732 & 90,289 & 103,923 & 122,497 & 146,792 \\
\cline { 2 - 9 } & 6 & $6,529,069$ & 11,893 & 12,920 & 14,432 & 16,570 & 19,453 & 23,179 \\
\cline { 2 - 9 } & 7 & $3,765,934$ & 11,709 & 12,716 & 14,187 & 16,248 & 18,996 & 22,507 \\
\cline { 2 - 8 } & Total & $89,884,645$ & 97,900 & 106,367 & 118,909 & 136,741 & 160,946 & 192,478 \\
\hline
\end{tabular}

\subsection{Return on investment per tier}

As previously seen, the covering algorithm ensures at least one $1^{\text {st }}$ tier winning ticket among the bets, with a $12.5 \%$ chance of having two winning tickets and $1.3 \%$ of having 3 or more. Let $Q$ be the random variable that describes the number of $1^{\text {st }}$ tier winning tickets among the ones bet and $Y_{5}$ the one that describes the associated return on investment associated with tickets with 5 correct matches. Considering that the $1^{\text {st }}$ tier jackpot stands at $J_{5}$, the probability of obtaining a return on investment $Y_{5}=y$ is:

$$
p\left(Y_{5}=y\right)=\sum_{q=1}^{\infty} p(Q=q) \cdot p\left(X_{5}=q\left(\frac{J_{5}}{y}-1\right)\right)
$$

Similarly, but now considering that the number of winning tickets for the $2^{\text {nd }}$ and $3^{\text {rd }}$ tiers are fixed and given by:

- $2^{\text {nd }}$ tier: $1,866,364 \times \frac{1}{64,107}+407,798 \times \frac{1}{21,658}+1,113,899 \times \frac{1}{9,409}=166$

- $3^{\text {rd }}$ tier: $1,866,364 \times \frac{1}{866}+407,798 \times \frac{1}{445}+1,113,899 \times \frac{1}{261}=7,332$ 
The distribution of returns obtained from lesser prizes is:

$$
\begin{gathered}
p\left(Y_{4}=y\right)=p\left(X_{4}=166\left(\frac{J_{4}}{y}-1\right)\right) \\
p\left(Y_{3}=y\right)=p\left(X_{3}=7,332\left(\frac{J_{3}}{y}-1\right)\right)
\end{gathered}
$$

The probability mass functions for the return in each of the tiers are illustrated in Figure 4.

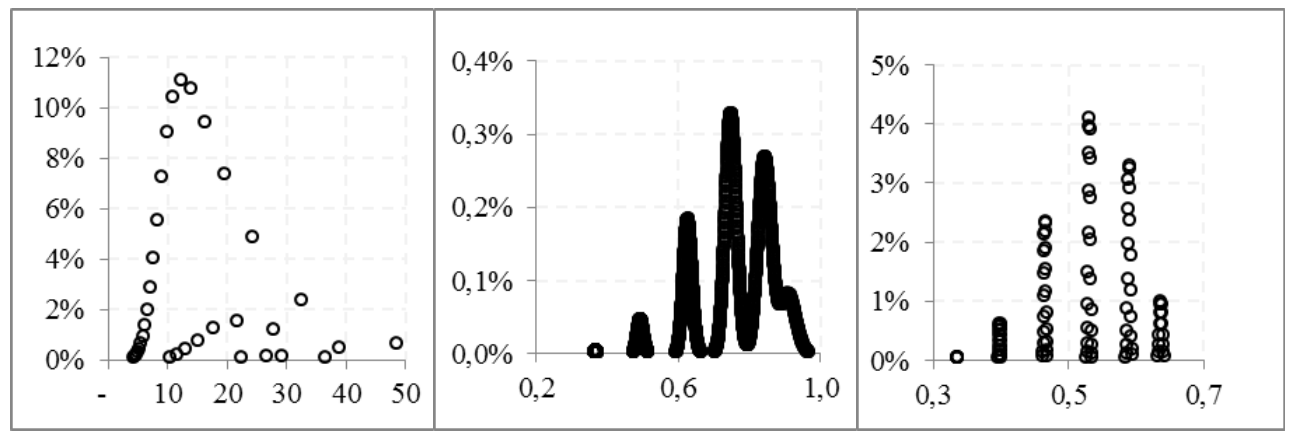

Figure 4 - Probability mass functions of return on investment in $\mathrm{R} \$$ millions for (a) $1^{\text {st }}$ prize tier, (b) $2^{\text {nd }}$ prize tier and (c) $3^{\text {rd }}$ prize tier (consolidated in groups of 100 data points).

It is worth noticing how the $1^{\text {st }}$ tier prize outweighs the minor prizes and the peaks in the distributions arising from the effect of the birthday numbers.

\subsection{Consolidated return on investment}

The total return on investment, $Y$, is calculated as the sum of the returns obtained from each prize tier, $Y=Y_{5}+Y_{4}+Y_{3}$. These variables, however, are not independent. For instance, when the number of third party winners in the $1^{\text {st }}$ tier is high due to a high count of birthday numbers drawn, so it tends to be in the $2^{\text {nd }}$ and $3^{\text {rd }}$ prize tiers.

To compensate for the dependency between these variables the returns on investment must be consolidated by the convolving the probability mass functions for each of the prize tiers conditioned to a certain number of birthday numbers drawn, $T_{b}$, and only then combined, so that:

$$
\begin{gathered}
p\left(Y_{5}+Y_{4}+Y_{3}=y\right) \\
=\sum_{t_{b}=0}^{5}\left\{p\left(Y_{5}=y \mid T_{b}=t_{b}\right) * p\left(Y_{4}=y \mid T_{b}=t_{b}\right) * p\left(Y_{3}=y \mid T_{b}=t_{b}\right) \times p\left(T_{b}=t_{b}\right)\right\}
\end{gathered}
$$

Evaluating this expression using MS Excel ${ }^{\circledR}$ and VBA, it is possible to determine the consolidated function for the gross return on investment, shown in Figure 5. 


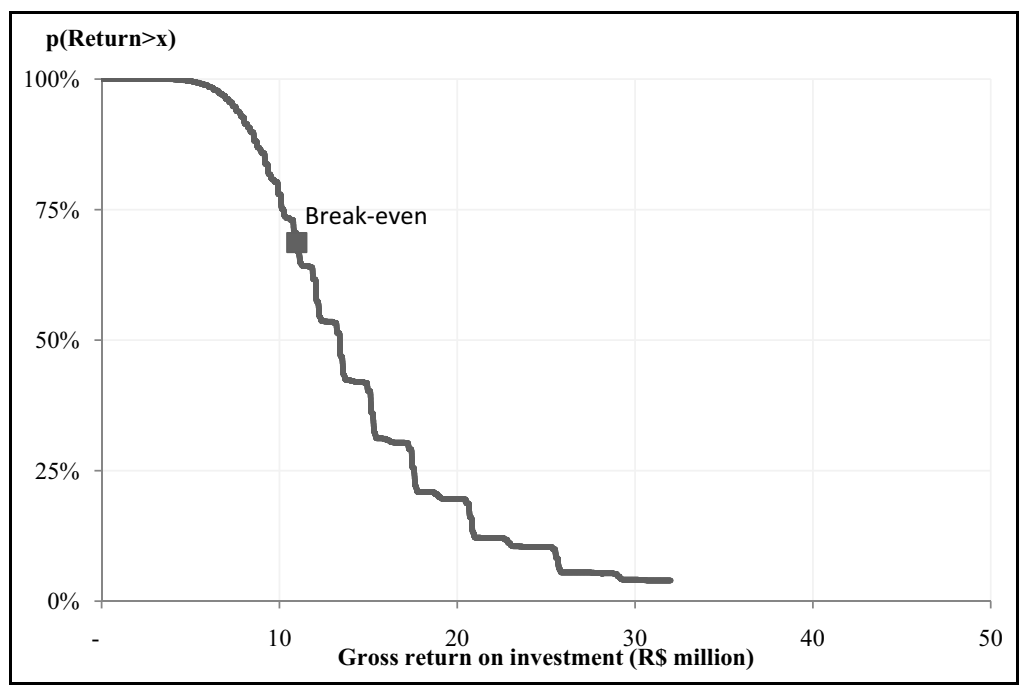

Figure 5 - Complementary cumulative probability function for gross return on investment.

\section{CONCLUSIONS AND FINAL RESULTS}

The analysis herein conducted shows that even well-defined problems, such as lottery games, may involve complex phenomena, requiring a careful analysis not to derive misleading insights.

The study evidences that certain kinds of bets have an economical advantage over others, allowing for 21 times the coverage for a price only 10 times higher. In spite of this economical advantage, roughly $89 \%$ of players choose to play with the cheapest, least efficient ticket, suggesting most of them do not fit a rational agent model.

It is also shown that, while $69 \%$ of players may be considered to select numbers randomly among the 80 available in the pool, the $31 \%$ remaining are twice more likely to select numbers between 1 and 31 , here called birthday numbers. As a consequence, the expected number of winners sharply rises when these numbers are drawn, increasing the investment's risk.

We also showed that the coverage of all the possible drawing's outcomes is not a trivial problem, requiring a heuristic approach to derive a solution that approaches the optimal. While one could initially estimate $\mathrm{R} \$ 8.6$ million would be necessary to cover all the possible results, the algorithm suggests that $\mathrm{R} \$ 11.0$ million are, in fact, needed to do so.

The consolidated results, on the other hand, estimates the expected return on investment to be R\$ 15.0 million, an upside of $37 \%$ over the initial investment, with a $12 \%$ chance of doubling the initial investment. On the other hand, there's also a $31 \%$ chance that the return won't make up for the amount invested and for $71 \%$ of these cases the net loss is higher than $\mathrm{R} \$ 1.0$ million.

Overall, the investment has a high expected return (expected net return is $\mathrm{R} \$ 4$ Million), but it also bears a high degree of risk exposure (there is a $31 \%$ chance of not recovering the investment). 
Considering both these points and the enormous operational difficulties for covering all necessary bets, our conclusion is that this unconventional investment opportunity should be recommended only for those with a huge appetite for risk.

Now, before we comment on the results related to the draw of June $24^{\text {th }}, 2013$, what we will do in the upcoming paragraphs, we find interesting to point out that above conclusions were precisely those that were presented on an early version of this paper that was submitted and accepted for publication on the Proceedings of the Brazilian Symposium on Operations Research (see Castello $\&$ Milioni, 2013). Therefore, above conclusions are previous to these results. Let us then present and comment on the final results of the Draw of June $24^{\text {th }}, 2013$.

As expected, the draw for the 2013 edition of Quina de São João was held on June, $24^{\text {th }}, 2013$. There was a considerable coverage from the media and the results can be found in many places, such as http://bit.ly/10I1jFd, for instance. In summary:

- The total prize for winners of the $1^{\text {st }}$ tier (5 correct matches) was $\mathrm{R} \$ 97.5$ million.

- The draw numbers were $05,17,55,63$ and 67 , i.e., two birthday numbers were draw.

- There were 15 winners on the $1^{\text {st }}$ tier and they shared $\mathrm{R} \$ 6.5$ million each.

We had predicted:

- A total prize of $\mathrm{R} \$ 97.0$ million for the first tier (see Table 5), a difference of only $0.6 \%$ when compared to the real value.

- That two birthday numbers were the most likely situation to occur, with a probability of $36 \%$ (see Table 6).

- That, in this case, the expected number of winners of the $1^{\text {st }}$ tier would be 7.7 almost exactly half of what really occurred (again, Table 6).

There is an important point to be considered, here. As it has been seen, our analysis focus only on the frequency that birthday numbers are selected, without taking in consideration specifically which were these numbers. In the draw held on June $24^{\text {th }}$ of 2013 , both birthday numbers that were selected, 5 and 17, are very popular among players (see Table 3). Number 5 appears on $2^{\text {nd }}$ place among all numbers, losing only to number 13 , while number 17 ranks $12^{\text {th }}$.

In fact, it is important to mention that above results reinforce the evidence of the hypothesis of player's bias.

As for the return of this "unconventional investment opportunity", in case a player ' $P$ ' had actually performed it, his expected return would be computed as follows (for the sake of simplicity, we will not take in consideration that the investment made by $P$ would affect the values of the prizes paid on each tier, since we noticed that, in practice, this effect is not very significant): 
- It is expected that $P$ had 166 wins on the $2^{\text {nd }}$ tier (see sub-section 2.12). Since there were 2,337 other winners on this tier and each one received a total of $\mathrm{R} \$ 4,398, P$ would expect to receive:

$$
166 * 2,337 * 4,398 /(2,337+166)=\mathrm{R} \$ 0.68 \text { million. }
$$

- Similarly, for the $3^{\text {rd }}$ tier, $P$ would expect to have 7,332 wins (see, again, sub-section 2.12), and $P$ would then expect to receive:

$$
7,332 * 130,118 * 113 /(130,118+7,332)=\mathrm{R} \$ 0.78 \text { million. }
$$

- Therefore, with a single win on the $1^{\text {st }}$ tier, $P$ would receive $6.50+0.68+0.78=\mathrm{R} \$ 7.96$ million. In this case, since the investment was $\mathrm{R} \$ 10.98$ million (see Table 4 ), $P$ would have lost R\$ 3.02 million.

- It is important to recall, however, that due to imperfections on the covering algorithm (see sub-section 2.7$), P$ had a probability of $12.5 \%(1.3 \%)$ of winning with two (three) tickets on the $1^{\text {st }}$ tier, cases in which $P$ 's total prize would be $\mathrm{R} \$ 13.29(\mathrm{R} \$ 18.19)$ million, a gain of R \$ 2.31 (7.21) million.

- Thus, $P$ 's expected return would be:

$$
-3.02 * 0.862+2.31 * 0.125+7.21 * 0.013=-\mathrm{R} \$ 2.22 \text { million. }
$$

Therefore, this "unconventional investment opportunity" that showed to be possibly good in 2011 and 2012 would have been catastrophic in 2013, with an expected loss of more than R \$ 2 million. In other words, beating the lottery, after all, is still a matter of luck.

\section{REFERENCES}

[1] Burger A P, Gründlingh WR \& VAn VuUren JH. 2003a. The Lottery Problem. Available at: $<$ http://dip.sun.ac.za/ vuuren/papers/lotery_artikel1oud.pdf>. Accessed 21 Oct. 2012.

[2] Burger AP, Gründlingh WR \& VAN VuUREn JH. 2003b. Two Combinatorial Problems involving Lottery Schemes: Algorithmic Determination of Solution Sets. Available at: $<$ http://bit.ly/ZPsCOS > . Accessed 21 Oct. 2012.

[3] Castello J \& Milioni AZ. 2013. Special Lottery Drawings - Analysis of an Unconventional Investment Opportunity, accepted for presentation and publication on the Proceedings of SBPO 2013 - Brazilian Symposium on Operations Research, September, 16 ${ }^{\text {th }}$ to $19^{\text {th }}$, Salvador, BA, Brazil, 2013.

[4] CEF (CAixa Econômica Federal). 2011. Circular Caixa no. 546, de 20 de abril de 2011. Superintendência Nacional de Loterias. Available at:

<http://www.normasbrasil.com.br/norma/circular-546-2011_11129.html>. Accessed 12 Oct. 2012.

[5] CEF (CAixa Econômica Federal). 2012. Quina. Loterias da Caixa. Available at: <http://www1.caixa.gov.br/loterias/loterias/quina > . Accessed 12 Oct. 2012. 
[6] DU PLESSIS A. 2010. On two combinatorial optimization problems involving lotteries. Thesis (Master of Commerce) - Stellenbosch University. Available at: <http://bit.ly/12gDhxG>. Accessed 21 Oct. 2012.

[7] Fog A. 2008. Calculation Methods for Wallenius' Noncentral Hypergeometric Distribution. Communications in Statistics, Simulation and Computation, 37(2): 258-273.

[8] Gordon DM, Kuperberg G, Patashnick O \& Spencer JH. 1995. Asymptotically Optimal Covering Designs. Available at: <http://www.ccrwest.org/gordon/optimal.pdf>. Acessed 12 Oct. 2012 .

[9] GRÜndlich WR. 2004. Two New Combinatorial Problems involving Dominating Sets for Lottery Schemes. Tese (Ph.D) Available at: < http://dip.sun.ac.za/ vuuren/Theses/Grundlingh.pdf > Acessed 12 Oct. 2012.

[10] Simons G \& Johnson NL. 1971. On the convergence of Binomial to Poisson distributions. The Annals of Mathematical Statistics, 42(5): 1735-1736.

[11] Thaler RH \& Ziemba WT. 1988. Parimutuel Betting Markets: Racetracks and Lotteries. Journal of Economic Perspectives, 2(2): 161-174. 